\title{
The effects of REV5901 on intracellular calcium signalling in freshly isolated bovine articular chondrocytes
}

\author{
Ala Qusous ${ }^{1,2}$, Eleanor Parker ${ }^{1}$, Niwa Ali ${ }^{3}$, Sajid G. Mohmand ${ }^{1}$ and Mark J. P. Kerrigan ${ }^{4}$ \\ ${ }^{1}$ School of Life Sciences, University of Westminster, 115 New Cavendish Street, London, United Kingdom \\ ${ }^{2}$ School of Life Science, University of Dundee, Perth Road, United Kingdom \\ ${ }^{3}$ King's College London School of Medicine, Guy's Hospital, London, United Kingdom \\ ${ }^{4}$ School of Science, University of Greenwich, Chatham Maritime, United Kingdom
}

\begin{abstract}
REV5901 is an inhibitor of regulatory volume decrease (RVD) a mechanotransduction pathway regulating cell volume in response to hypotonicity, with protective properties upon chondrocyte trauma impact in situ. As the mechanism of action of REV5901 is unknown and changes in intracellular calcium $\left(\left[\mathrm{Ca}^{2+}\right]_{\mathrm{i}}\right)$ have been linked to REV5901-loading, we investigated the effects of REV5901 on a known calcium signalling pathway. Upon REV5901 loading, there was significant increase in $\left[\mathrm{Ca}^{2+}\right]_{\mathrm{i}}$ reaching $37.97 \pm 5.67 \%$, above basal levels which was reduced to $27.86 \pm 3.15 \%$ in the presence of $2 \mathrm{mmol} / \mathrm{l}$ EGTA. In the presence of U73122 or neomycin there was a decrease in calcium with inhibition factors (I.F.) of $0.39 \pm 0.09$ and $0.37 \pm 0.08$, respectively, whereas rottlerin abolished the REV5901-induced $\left[\mathrm{Ca}^{2+}\right]_{\mathrm{i}}$ rise. The role of calcium channels in contributing to the REV5901-induced calcium rise was investigated whereby the calcium rise was inhibited in the absence of extracellular sodium and by the addition of $\mathrm{Gd}^{3+}$ and Ruthenium red. These data show a phospholipase $\mathrm{C} \beta 3$-dependent release of calcium from intracellular stores as well as a sodium calcium exchanger-mediated influx in response to REV5901 loading, suggesting a potential role for calcium signalling in mediating the action of REV5901 in chondrocytes.
\end{abstract}

Key words: Gadolinium - NCX - PKC - Ruthenium red - Regulatory volume decrease

\begin{abstract}
Abbreviations: $\left[\mathrm{Ca}^{2+}\right]_{\mathrm{i}}$, intracellular calcium; GPCR, G-protein coupled receptor; $\mathrm{IP}_{3}$, inositol triphosphate; NCX, sodium calcium exchanger, PIP2, phosphatidylinositol 4,5-bisphosphate; PIP3, phosphatidylinositol $(3,4,5)$-trisphosphate; RVD, regulatory volume decrease; SACC, stretch-activated cation channel; TRPV, transient receptor potential vanilloid.
\end{abstract}

\section{Introduction}

Chondrocytes within articular cartilage possess the capacity to 'sense' and convert mechanical stimuli into chemical and physiological responses using a group of mechanisms termed mechanotransduction. Mechanotransduction enables chondrocytes to adapt and respond to the changes in their extracellular environment to maintain an optimal intracellular environment and/or modify extracellular matrix components (Urban et al. 1993). In response to

Correspondence to: Ala Qusous, School of Life Science, University of Dundee, Perth Road, United Kingdom

E-mail: A. Qusous@dundee.ac.uk a decrease in extracellular osmolality, chondrocytes exhibit the capacity for regulatory volume decrease (RVD), which mediates the loss of osmolytes and associated water, thereby resulting in shrinkage and recovery of cell volume. Changes in concentration of intracellular calcium $\left(\left[\mathrm{Ca}^{2+}\right]_{i}\right)$, a secondary messenger, have been closely linked to changes in osmolality (Urban et al. 1993; Hopewell and Urban 2003; Kerrigan and Hall 2005; Kerrigan et al. 2006) amongst other mechanical signals. Previous work has shown that calcium enters the cytoplasm of chondrocytes through i) cell membrane calcium channels including stretch-activated cation channel (SACC), transient receptor potential vanilloid (TRPV; Sanchez et al. 2003) channels or sodium calcium exchanger (NCX; Sanchez and Wilkins 2004), or 
ii) via inositol triphosphate $\left(\mathrm{IP}_{3}\right)$-induced and/or a G-protein-mediated release from intracellular stores (Yellowley et al. 1997, 1999).

NCX is regulated by $\left[\mathrm{Ca}^{2+}\right]_{i}$ and is found on both the plasma membrane and intracellular organellar membranes (Gabellini, 2004). SACC, conversely, is a group of $\mathrm{Gd}^{3+}$-sensitive channels that respond to mechanical 'stress' by allowing the exchange of cations. It has been shown that chondrocytes exhibited a transient increase in $\left[\mathrm{Ca}^{2+}\right]_{\mathrm{i}}$ in a $\mathrm{Gd}^{3+}$-sensitive manner in response to a hypotonic challenge (Kerrigan and Hall 2008), possibly mediated by PLC/IP 3 -dependent calcium release from intracellular stores (Sanchez et al. 2003), whereas only NCX has been shown to be involved in hypertonicityinduced $\left[\mathrm{Ca}^{2+}\right]_{\mathrm{i}}$ rise (Sanchez and Wilkins 2004). TRPV channels are non-selective cation channels which transport calcium in non-excitable cells, with TRPV4 linked to the capacity for RVD in keratinocytes and epithelial cells (Becker et al. 2005; Pan et al. 2008). Together these data suggest that there is a strong relationship between $\left[\mathrm{Ca}^{2+}\right]_{\mathrm{i}}$ and mechanotransduction, and thus the relationship between RVD and $\left[\mathrm{Ca}^{2+}\right]_{\mathrm{i}}$ is an area of continuing research.

REV5901 is an antagonist of cysteinyl-leukotriene receptors (a family of G-protein coupled receptor; GPCR) in porcine epithelial cells (Van Inwegen et al. 1987) and has been shown to inhibit RVD in articular chondrocytes (Bush and Hall 2001). Interestingly preliminary observations in our research group have shown that REV5901-loading induced a sustained rise in $\left[\mathrm{Ca}^{2+}\right]_{\mathrm{i}}$, thus offering a potential mechanism by which chondrocyte RVD is inhibited. Additionally, others in our research group have shown that incubation with REV5901 offers calcium-dependent, shrinkage-associated, chondro-protective properties upon impact trauma (Nedelcheva et al. 2010; Parker et al. 2011).

To determine a potential mechanism of the effects of REV5901 on chondrocytes, here we studied changes in $\left[\mathrm{Ca}^{2+}\right]_{\mathrm{i}}$ in response to REV5901 loading using a fluorescent plate reader (BMG Labtech), whereby changes in $\left[\mathrm{Ca}^{2+}\right]_{\mathrm{i}}$ were determined in fluo-4 loaded freshly isolated bovine articular chondrocytes. As the mechanism of the REV5901-induced $\left[\mathrm{Ca}^{2+}\right]_{\mathrm{i}}$ rise is currently unknown, here we determined the effect of REV5901 on a known GPCR-mediated pathway to provide a novel understanding of the mechanism by which REV5901 plays a role in chondrocyte mechanotransduction responses, including RVD inhibition and chondro-protection.

\section{Materials and Methods}

\section{Culture media and experimental salines}

All materials used were supplied by Sigma (Poole, UK) unless otherwise stated. Tissue culture media used was 380 $\mathrm{mOsm} \cdot \mathrm{kg}^{-1}$ Dulbecco's Modified Eagle Medium (DMEM) supplemented with $1 \%$ penicillin/streptomycin solution and $50 \mathrm{mmol} / \mathrm{l} \mathrm{NaCl}$ under asceptic conditions. As phenol red in media interferes with calcium measurement, experiments were performed using basic physiological saline (BPS) containing (in mmol/l): HEPES 15, glucose $10, \mathrm{KCl} 5, \mathrm{MgCl}_{2} 2$ and $\mathrm{CaCl}_{2} 1$. The $\mathrm{pH}$ was adjusted to $7.40 \pm 0.05$ and the osmolarity measured using Vapro $^{\mathrm{TM}}$ vapour pressure osmometer (Wescor, Essex, UK), adjusted by the addition of $\mathrm{NaCl}$. When performing 'calcium-free' experiments $\mathrm{CaCl}_{2}$ was replaced with $2 \mathrm{mmol} / \mathrm{l}$ EGTA and when performing sodium-free experiments the osmolarity was adjusted by the addition of choline chloride (Dascalu et al. 1996).

\section{Chondrocyte isolation and culture}

Bovine metacarpal and metatarsal joints of freshly slaughtered 18-21 month-old female animals were obtained from the local abattoir (with permission from the UK Department for Environment, Food and Rural Affairs), full-depth cartilage isolated into $280 \mathrm{mOsm}$ DMEM supplemented with $1 \%$ penicillin/streptomycin solution under aseptic conditions and chondrocytes isolated as previously described (Hall et al. 1996). Cartilage explants were incubated overnight in $380 \mathrm{mOsm}$ DMEM supplemented with $1 \%$ penicillin/ streptomycin solution and $0.8 \mathrm{mg} / \mathrm{ml}$ collagenase. After the overnight incubation period, the samples were passed through a sterile tea-strainer and $40 \mu \mathrm{m}$ filter to remove any non-digested material. They were then washed by centrifugation twice at $600 \mathrm{~g}$ for 10 minutes. Following the final wash, the chondrocyte pellet was resuspended in fresh $380 \mathrm{mOsm}$ DMEM and the cells used within 8 hours.

\section{Calcium imaging}

Changes in intracellular calcium were determined using a fluorescence plate (BMG LabTech) reader in conjunction with fluo-4 (Invitrogen; Paisley, UK), a calcium indicator that provides a rapid and proven method of imaging intracellular calcium flux (Gandhi et al. 2000), as previously described (Ali et al. 2008; Nair et al. 2011). Chondrocytes were seeded onto a 12 -well plates at $2 \times 10^{4} \mathrm{cell} / \mathrm{cm}^{2}$ (Waymouth, 1974) and allowed to adhere prior to incubation with $3 \mu \mathrm{mol} / \mathrm{l}$ fluo- 4 for 30 minutes at $37^{\circ} \mathrm{C}$. Media was replaced with BPS to remove excess dye and initial calcium measurement was taken prior to loading 1:1 volume $100 \mu \mathrm{mol} / \mathrm{l}$ REV5901 (final concentration of $50 \mu \mathrm{mol} / \mathrm{l}$; Cambridge Biosciences; Cambridge, UK; (Bush and Hall 2001)) and observing changes in $\left[\mathrm{Ca}^{2+}\right]_{\mathrm{i}}$ for 5 minutes by exciting fluo- 4 at $494 \mathrm{~nm}$ and collecting at $520 \mathrm{~nm}$.

For the purposes of investigating individual channel and/or signalling molecule contribution to the calcium rise, various inhibitors were employed (Table 1). Sodium- 
sensitive calcium influx (mediated but not exclusively by the NCX) was inhibited by the use of $\mathrm{Na}^{+}$-free BPS (Sanchez and Wilkins 2004). SACC and TRPV were inhibited by the use of $100 \mu \mathrm{mol} / \mathrm{l} \mathrm{Gd}^{3+}$ (Kerrigan and Hall, 2008) or $10 \mu \mathrm{mol} / \mathrm{l}$ ruthenium red (Gunthorpe et al. 2002), respectively. Pharmacological inhibitors were added to culture media with fluo- 4 and incubated for 30 minutes before being replaced with BPS (containing the same inhibitor) and loading 1:1 volume $100 \mu \mathrm{mol} / \mathrm{l} \mathrm{REV5901} \mathrm{(final} \mathrm{concentration} \mathrm{of}$ $50 \mu \mathrm{mol} / \mathrm{l})$ solution.

\section{Statistical analysis}

All statistical analysis and plotting of graphs were performed using Microsoft ${ }^{\circledR}$ Excel 2004. Rates of calcium change, found to be exponential, were calculated using linear regression. All values are shown as mean \pm standard error of the mean (S.E.M.). Two-tailed homoscredastic Student's $t$-tests were carried out. In order to reduce the effects of any genetic variation, experiments were performed with chondrocytes obtained from as many animals as possible. The inhibition factor (I.F.) of various pharmacological inhibitors was determined as the difference between $\left[\mathrm{Ca}^{2+}\right]_{\mathrm{i}}$ rise in the presence of the inhibitor and REV5901 and was expressed relative to solely REV5901-induced $\left[\mathrm{Ca}^{2+}\right]_{\mathrm{i}}$ rise.

\section{Results}

Optimisation of the calcium imaging protocol

As previous work in chondrocytes has shown that fluid flow elicits a rise in $\left[\mathrm{Ca}^{2+}\right]_{\mathrm{i}}$ (Yellowley et al. 1997), the loading speed of the fluorescent plate reader was first optimised to compensate for this. Calcium-bound fluo- 4 was excited at $494 \mathrm{~nm}$ and the basal cellular fluorescence measured for $56 \mathrm{~s}$ at $520 \mathrm{~nm}$ bandpass prior to BPS loading at either 420 or $260 \mu \mathrm{l} / \mathrm{s}$, and the subsequent fluorescence intensity being recorded every $14 \mathrm{~s}$ for $5 \mathrm{~min}$ (Figure 1A). At 420 $\mu \mathrm{l} / \mathrm{s}$, there was an immediate rise in $\left[\mathrm{Ca}^{2+}\right]_{\mathrm{i}}$ reaching 4.71 $\pm 0.32 \% 5 \mathrm{~min}$ post loading, whereas the effects of fluid flow were diminished at $260 \mu \mathrm{l} / \mathrm{s}$ as seen by the slight rise in calcium of $1.43 \pm 0.54 \%$ ( $p>0.05$; when compared to non-injected controls). These data confirm that $260 \mu \mathrm{l} / \mathrm{s}$ was the injection speed deemed most suitable for further experiments as it elicited a minimal change in $\left[\mathrm{Ca}^{2+}\right]_{\mathrm{I}}$ due to fluid flow.

To further optimise the protocol for $\left[\mathrm{Ca}^{2+}\right]_{\mathrm{i}}$ measurement, ionomycin, a calcium salt that facilitates $\mathrm{Ca}^{2+}$ transport across the cell membrane, was used at $3 \mu \mathrm{mol} / \mathrm{l}$ as a positive control (Liu and Hermann, 1978) and $4 \mu \mathrm{l} / \mathrm{ml}$ DMSO (drug solvent) as a negative control. DMSO solution induced a 1.55 $\pm 0.54 \%$ rise in $\left[\mathrm{Ca}^{2+}\right]_{\mathrm{i}}$ which was not significantly different

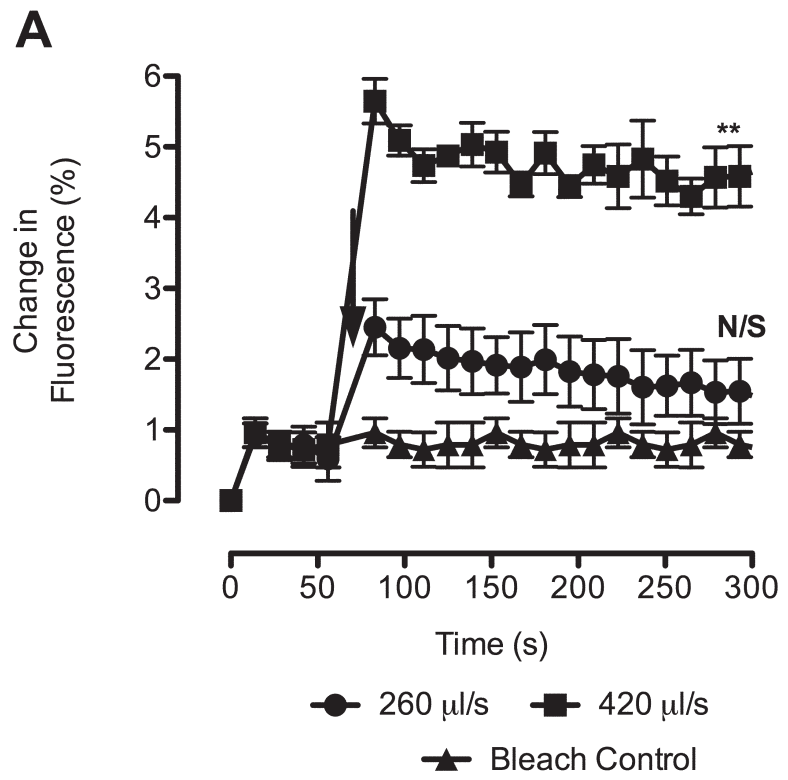

B

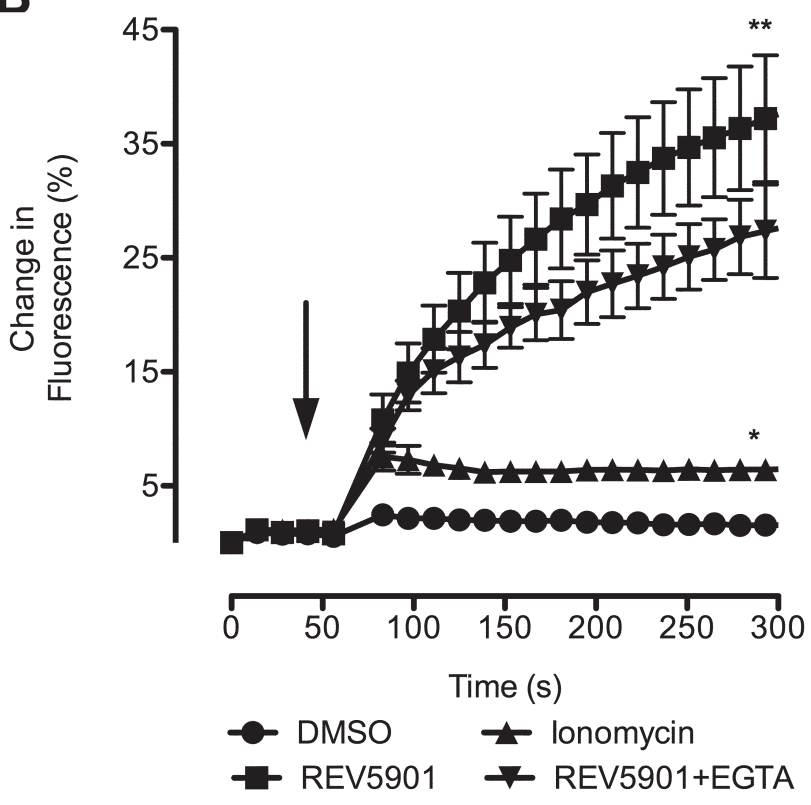

Figure 1. The optimisation of calcium measurement protocol. A. Freshly isolated chondrocytes were seeded onto 12 well plates and incubated in DMEM containing $3 \mu \mathrm{mol} / \mathrm{l}$ Fluo- 4 and the fluorescence measured every $14 \mathrm{~s}$ for $5 \mathrm{~min}$ post-fluid flow. Whilst at $420 \mu \mathrm{l} / \mathrm{s}$ there was a rise in $\left[\mathrm{Ca}^{2+}\right]_{\mathrm{i}}$ of $4.71 \pm 0.32$, the use of $260 \mu \mathrm{l} / \mathrm{s} \mathrm{did} \mathrm{not}$ induce a significant rise. Experiment was performed once, $n=3$. B. The methodology devised for the measurement of changes in $\left[\mathrm{Ca}^{2+}\right]_{\mathrm{i}}$ was assayed using Ionomycin, DMSO solution induced a 1.55 $\pm 0.54 \%$ rise in $\left[\mathrm{Ca}^{2+}\right]_{\mathrm{i}}$ (equivalent to the rise induce by fluid flow), whereas Ionomycin caused an influx of $\mathrm{Ca}^{2+}$ of $6.52 \pm 0.74 \%$, thus indicating that the methodology is suitable for the purposes of this research REV5901 induced a rise in $\left[\mathrm{Ca}^{2+}\right]_{\mathrm{i}}$ of $37.97 \pm 5.67 \%$ which was inhibited in the presence of $2 \mathrm{mmol} / \mathrm{l}$ EGTA to $27.86 \pm 3.17 \%$. $n=3$, experiment repeated 6 times. Data shown as means \pm S.E.M. T-test $p$-values : ${ }^{\star} p<0.05$ and ${ }^{* *} p<0.01$. N/S, non significant. 
from the effects induced by fluid flow $(p>0.05)$. Ionomycin caused an influx of calcium raising $\left[\mathrm{Ca}^{2+}\right]_{\mathrm{i}}$ levels by $6.52 \pm$ $0.74 \%(p<0.01$; Figure $1 \mathrm{~B})$, thus confirming that the methodology was suitable for measuring changes in $\left[\mathrm{Ca}^{2+}\right]_{\mathrm{i}}$.

The effect of REV5901 loading on $\left[\mathrm{Ca}^{2+}\right]_{i}$

Having determined the suitability of the protocol, the effect of REV5901 on $\left[\mathrm{Ca}^{2+}\right]_{i}$ was investigated in fluo-4-loaded chondrocytes. Upon loading of REV5901 solution (final concentration $50 \mu \mathrm{mol} / \mathrm{l})$ a significant and sustained rise in $\left[\mathrm{Ca}^{2+}\right]_{\mathrm{i}}$ levels by $37.97 \pm 5.67 \%(p>0.01$; Figure $1 \mathrm{~B})$ was observed compared to DMSO negative control loading. Furthermore, unlike ionomycin, REV5901-induced calcium rise did not reach a plateau remaining in elevation for the duration of the experiment (at least $5 \mathrm{~min}$ ) at an average rate of $\left[\mathrm{Ca}^{2+}\right]_{\mathrm{i}}$ rise of $7.35 \pm 0.80 \% \mathrm{~min}^{-1}$.

In order to determine the source of the REV5901-mediated $\left[\mathrm{Ca}^{2+}\right]_{\mathrm{i}}$ rise, the contribution of trans-membranous influx was investigated in the absence of extracellular calcium in BPS supplemented with $2 \mathrm{mmol} / \mathrm{l}$ EGTA, whereby the REV5901-induced calcium rise was reduced to $27.86 \pm$ $3.17 \%$ ( $p<0.05$; relative to DMSO control), thus suggesting that intracellular calcium stores part-contributed to the REV5901-induced rise in $\left[\mathrm{Ca}^{2+}\right]_{\mathrm{i}}$ as well as, to a lesser extent, an influx from the extracellular medium (Figure 1B).

The mechanism of intracellular calcium rise in response to REV5901

Having determined that the REV5901-induced rise in $\left[\mathrm{Ca}^{2+}\right]_{\mathrm{i}}$ was predominantly due to a release from intracellular stores, the role of G-protein-signalling was subsequently investigated using inhibitors of key signalling molecules and proteins (Table 1). $1 \mu \mathrm{mol} / \mathrm{l}$ wortmannin, an inhibitor of phosphatidylinositol 5-kinase (PI5K; Liu et al. 2001)), did not cause inhibition of the REV5901-mediated calcium rise, indicating the lack of PI5K contribution to the
REV5901 signal (I.F. $=0.04 \pm 0.03$; Figure 2). Neomycin sequestering of $\mathrm{IP}_{3}$ molecules reduced the initial calcium 'burst' to $7.16 \pm 1.66 \%$ (compared to $10.78 \pm 1.30 \%$ in REV5901-loaded chondrocytes) with maximum $\left[\mathrm{Ca}^{2+}\right]_{\mathrm{i}}$ rise of $23.79 \pm 2.21 \%(p<0.01)$, thereby reducing the overall rate of $\left[\mathrm{Ca}^{2+}\right]_{\mathrm{i}}$ rise from $7.35 \pm 0.80 \% \cdot \mathrm{min}^{-1}$ in REV5901-loaded chondrocytes to $4.55 \pm 0.49 \% \cdot \mathrm{min}^{-1} .100$ $\mu \mathrm{mol} / 1 \mathrm{U} 73122$ (inhibitor of phosopholipase C 33 , PLC $\beta 3$ ) decreased the rate of $\left[\mathrm{Ca}^{2+}\right]_{\mathrm{i}}$ rise to $4.79 \pm 0.52 \% \cdot \mathrm{min}^{-1}$ thus reaching a final increase of $23.09 \pm 2.70 \%(p<0.01)$. Finally the incubation with $100 \mu \mathrm{mol} / \mathrm{l}$ Rottlerin diminished the REV5901-induced $\left[\mathrm{Ca}^{2+}\right]_{\text {i }}$ rise to $2.27 \pm 3.30 \%$, thus inhibiting the REV5901-mediated calcium rise $(p<$ 0.05 relative to DMSO control). Upon examining the I.F. of pharmacological inhibitors (Figure 2B), it was apparent that the REV5901-induced $\left[\mathrm{Ca}^{2+}\right]_{\mathrm{i}}$ rise was dependent on protein kinase $\mathrm{C}(\mathrm{PKC})$ activity, with rottlerin dispaying an I.F. of $0.94 \pm 0.02$, and to a lesser extent PLC $\beta 3$ and $\mathrm{IP}_{3}$ concentration (U73122 I.F. $=0.39 \pm 0.07$ and neomycin I.F. $=0.37 \pm 0.06)$ but not PI5K concentration.

\section{Membrane channel contribution to $\left[\mathrm{Ca}^{2+}\right]_{i}$ rise in response to REV5901-loading}

To investigate the role of membrane channel-dependent $\left[\mathrm{Ca}^{2+}\right]_{\mathrm{i}}$ influx in mediating REV5901-induced $\left[\mathrm{Ca}^{2+}\right]_{\mathrm{i}}$ rise, inhibition of calcium channels with previously determined roles was performed using pharamacological inhibitors or physiological inhibitory conditions (Figure $3 \mathrm{~A})$. In the absence of extracellular sodium $\left(\left[\mathrm{Na}^{+}\right]_{\mathrm{e}}\right)$, there was a reduction in the maximal REV5901-induced $\left[\mathrm{Ca}^{2+}\right]_{\mathrm{i}}$ rise to $6.07 \pm$ $3.50 \%(p<0.05$; relative to DMSO control), equivalent to an I.F. of $0.84 \pm 0.09$, indicating a dependency on sodiumsensitive calcium channels in freshly isolated chondrocytes. Additionally, in the presence of $\mathrm{Gd}^{3+}$, the inhibition of $\left[\mathrm{Ca}^{2+}\right]_{\mathrm{i}}$ rise was observed with maximal rise in fluorescence reaching $25.43 \pm 1.53 \%$ ( $p<0.01$ relative to DMSO control) and I.F. of $0.33 \pm 0.04$. Finally, similar inhibitory effects were

Table 1. Pharmacological agents used in the investigation of the REV5901-induced calcium signal

\begin{tabular}{|c|c|c|c|}
\hline Substance $(\mu \mathrm{mol} / \mathrm{l})$ & Target & Comments & References \\
\hline REV5901 (50) & Cysteinyl-leukotriene receptors & Inhibitor of RVI and lipoxygenase & $\begin{array}{l}\text { Bush and Hall } 2001 \\
\text { Musser et al. } 1987 \\
\text { Van Inwegen et al. } 1987\end{array}$ \\
\hline U73122 (100) & PLC $\beta 3$ & Highly selective & Hou et al. 2004 \\
\hline Wortmannin (1) & PI5K & Inhibits PI3K & Liu et al. 2001 \\
\hline Rottlerin (100) & PKC & Activates $\mathrm{K}^{+}$channels & Gschwendt et al. 1994 \\
\hline Neomycin $\left(10^{4}\right)$ & IP3 & Used at $55 \mu \mathrm{mol} / \mathrm{l}$ in culture as antibiotic & James et al. 2004 \\
\hline Ruthenium red (10) & TRPV & Inhibits ryanodine receptors and NCX & Gunthorpe et al. 2002 \\
\hline Gadolinium (100) & SACC & - & Sackin 1995 \\
\hline Ionomycin (3) & Mobile calcium carrier & Greater selectivity for $\mathrm{Ca}^{2+}$ over $\mathrm{Mg}^{2+}$ & Liu and Hermann 1978 \\
\hline
\end{tabular}


observed upon the use of ruthenium red with I.F. of $0.46 \pm$ 0.07 and maximal calcium rise of $20.37 \pm 2.53 \%(p<0.05$ relative to DMSO control; Figure 3B). Together, these data have demonstrated a role for the NCX and to a lesser extent SACC and TRPV channels in mediating the $\left[\mathrm{Ca}^{2+}\right]_{\mathrm{i}}$ rise following the loading of REV5901.

\section{Discussion}

Mechanotransduction is the term used to describe the processes by which chondrocytes 'respond' to extracellular mechanical stimuli by initiating cellular signalling pathways often involving the regulation of $\left[\mathrm{Ca}^{2+}\right]_{i}$ levels. Intracellular calcium is a key regulator of various intracellular functions and changes in $\left[\mathrm{Ca}^{2+}\right]_{\mathrm{i}}$ levels have been observed in response to various mechanical stimuli. As the incubation with REV5901 has been shown to provide chondro-protection from impact trauma by reducing the resting cell volume (Parker et al. 2010) and to inhibit RVD (Bush and Hall 2001), it may be suggested that REV5901 acts by activating $\mathrm{Ca}^{2+}$ dependent RVD mechanisms under isotonic conditions (Parker et al. 2011) whilst inhibiting others. The effect of REV5901 loading on $\left[\mathrm{Ca}^{2+}\right]_{i}$ was therefore investigated in freshly isolated bovine articular chondrocytes.

The REV5901-induced signalling pathway was investigated using pharmacological inhibitors of selected intracellular proteins/molecules involved in known calcium regulatory signals. GPCR have been shown to induce the activation of G-proteins which in turn induce a $\left[\mathrm{Ca}^{2+}\right]_{\mathrm{i}}$ rise via IP3 production in various cell types including leukocytes and epithelial cells (Verghese et al. 1986; Muallem and Wilkie 1999; Liu and Wu 2004). The necessity for IP3 in REV5901 calcium modulation was confirmed by prior incubation with $10 \mathrm{mmol} / \mathrm{l}$ neomycin (James et al. 2004) where it was observed that the latter attenuated the initial calcium response and thus exhibited a reduced maximal $\left[\mathrm{Ca}^{2+}\right]_{\mathrm{i}}$ rise. Similarly, the role of IP3 in $\left[\mathrm{Ca}^{2+}\right]_{\mathrm{i}}$ has been previously seen in chondrocytes whereby an inhibition of hypotonicity-induced calcium rise was abolished using neomycin (Sanchez et al. 2003).

Incubation with wortmannin, an inhibitor of PI5K at $100 \mathrm{nmol} / \mathrm{l}$ (Liu et al. 2001), prior to REV5901-loading did not have a significant effect on $\left[\mathrm{Ca}^{2+}\right]_{\mathrm{i}}$ rise, indicating that REV5901-induced $\left[\mathrm{Ca}^{2+}\right]_{\mathrm{i}}$ rise was not PI5K-dependent and therefore not mediated by Phosphatidylinositol $(3,4,5)$-trisphosphate (PIP3) pathway. The significance of phosphatidylinositol 4,5-bisphosphate (PIP2) pathway in REV5901-induced $\left[\mathrm{Ca}^{2+}\right]_{\mathrm{i}}$ was thus investigated using U73122, a pharmacological inhibitor of PLC $\beta 3$ at $100 \mu \mathrm{mol} / \mathrm{l}$ (Hou et al. 2004), where a reduction in the rate of $\left[\mathrm{Ca}^{2+}\right]_{i}$ rise was observed, confirming that REV5901 may act via PLC $\beta 3$ activation.

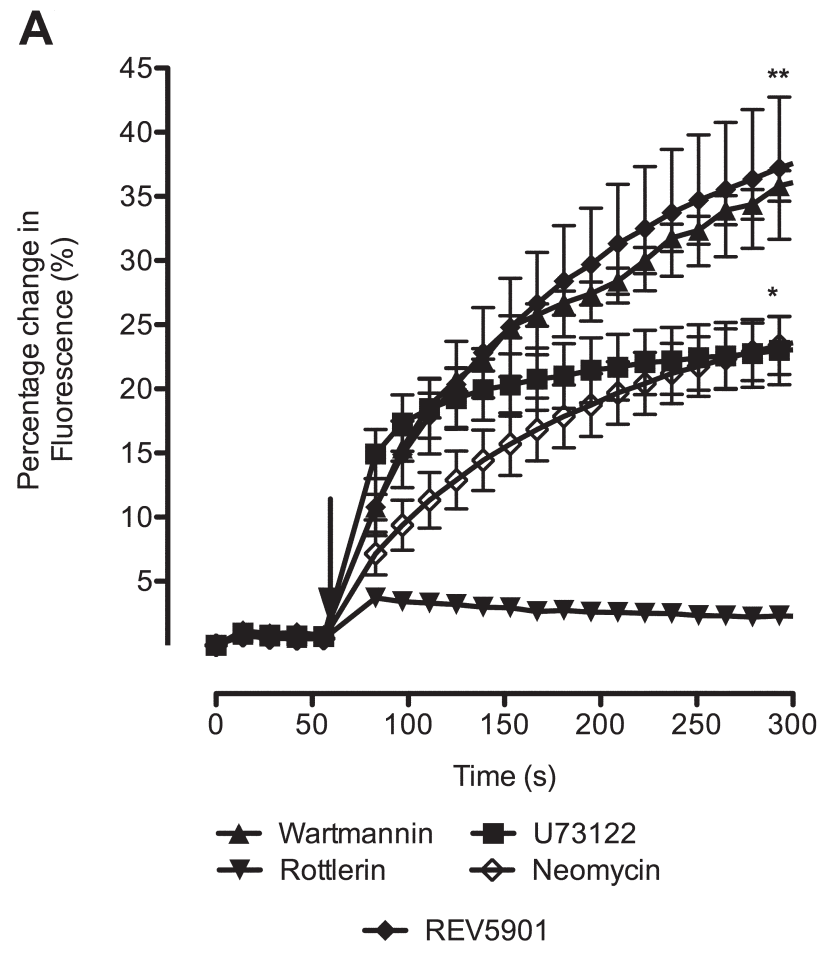

B

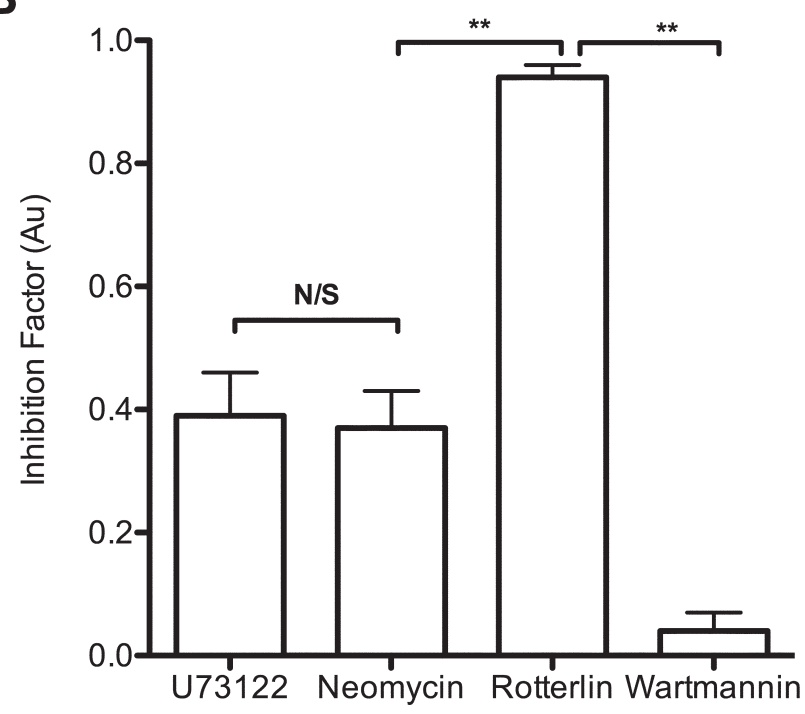

Figure 2. Changes in $\left[\mathrm{Ca}^{2+}\right]_{\mathrm{i}}$ in response to REV5901 loading in the presence of pharmacological inhibitors to G-protein downstream elements. Freshly isolated chondrocytes were incubated for $30 \mathrm{~min}$ with $3 \mu \mathrm{mol} / \mathrm{l}$ fluo- 4 and suitable pharmacological agents required to inhibit signalling molecules downstream of G-proteins prior to loading $50 \mu \mathrm{mol} / \mathrm{l}$ REV5901. Rottlerin reduced the maximal calcium rise to $2.27 \%$ (A) compared to REV5901 and both U73122 and neomycin caused an overall inhibition factor of $<0.38 \%$ (B) with neomycin also causing a distinctive reduction in the original burst of $\left[\mathrm{Ca}^{2+}\right]_{\mathrm{i}} \cdot n=4$, experiment repeated 6 times. Data shown as means \pm S.E.M.. T-test $p$-values: ${ }^{*} p<0.05$ and ${ }^{* *} p<0.01$. N/S, non significant. 
A

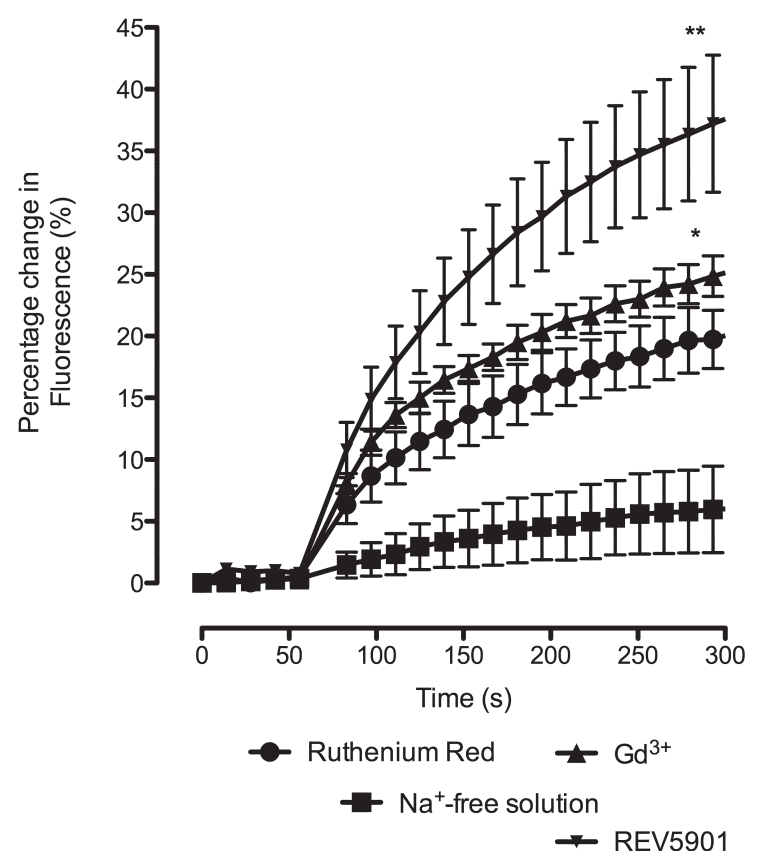

B

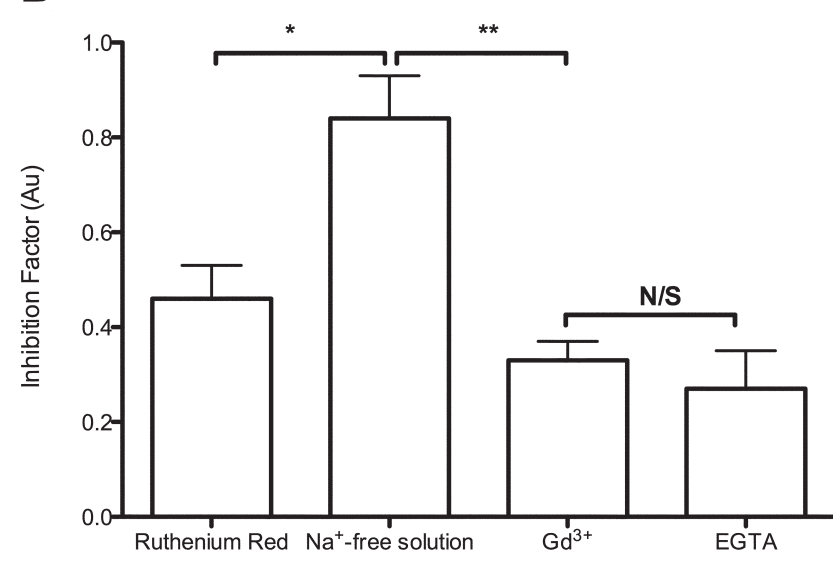

Figure 3. The effect of calcium channel inhibitors on REV5901induced $\left[\mathrm{Ca}^{2+}\right]_{\mathrm{i}}$ rise chondrocytes. Freshly isolated chondrocytes were incubated with $3 \mu \mathrm{mol} / \mathrm{l}$ fluo- 4 in BPS for $30 \mathrm{~min}$ prior to loading of $50 \mu \mathrm{mol} / \mathrm{L}$ REV 5901. In the presence of $75 \mathrm{mmol} / \mathrm{l} \mathrm{Ru}$ thenium Red and $100 \mu \mathrm{mol} / \mathrm{l} \mathrm{Gd}^{3+}$, there was a drop in maximum $\left[\mathrm{Ca}^{2+}\right]_{\mathrm{i}}$ rise to $20.37 \pm 2.53 \%$ and $25.43 \pm 1.53 \%$, respectively. In the absence of extracellular sodium, there was a significant reduction in $\left[\mathrm{Ca}^{2+}\right]_{i}$ with a maximal rise of $6.07 \pm 3.50 \%$ (A). The corresponding inhibition factors (I.F.) further demonstrated the enhanced dependency on extracellular sodium-mediated calcium influx (B). These data indicated a role for NCX and to a less extent SACC and TRPV channels in mediating REV5901-induced calcium influx. $N=6$, experiment repeated 4 times. Data shown as means \pm S.E.M. T-test $p$-values: ${ }^{\star} p<0.05$ and ${ }^{* *} p<0.01$. N/S, non significant.
The PLC 33 -mediated signalling pathway was further investigated by the inhibition of PKC using $100 \mu \mathrm{mol} / \mathrm{l}$ rottlerin (Gschwendt et al. 1994) which reduced the $\left[\mathrm{Ca}^{2+}\right]_{\mathrm{i}}$ rise to $2.27 \pm 0.61 \%$, thus suggesting a role for PKC in augmenting the signal by possibly further activating PLC $\beta 3$ proteins. The inhibitory effect of Rottlerin may, however, be grossly overestimated as reports have demonstrated an inhibitory effect of Rottlerin on other kinase and non-kinase proteins in vitro (Davies et al. 2000) including potassium channels (Zakharov et al. 2005). Nevertheless, it was concluded that REV5901 induced (but not exclusively) the activation of a signal mediated by PLC $\beta 3$, PKC and IP3 molecules required for $\left[\mathrm{Ca}^{2+}\right]_{\mathrm{i}}$ release from intracellular stores by IP3 receptors (IP3R; Figure 4).

Differences in the magnitude of inhibition between U73122, neomycin and rottlerin were noticeable, whereby both $\mathrm{U} 73122$ and neomycin reduced the $\left[\mathrm{Ca}^{2+}\right]_{\mathrm{i}}$ rise to $<23.00 \%$ (average I.F. of $<0.38$ ), a value non-significantly different to that obtained in the presence of $2 \mathrm{mmol} / \mathrm{l}$ EGTA, thus suggesting that IP3-mediated calcium release from intracellular stores may not be necessary for calcium influx across the plasma membrane. The role of PKC activation and IP3 generation in mediating a rise in $\left[\mathrm{Ca}^{2+}\right]_{\mathrm{i}}$ via GCPR has been previously observed in chondrocytes in response to incubation with histamine and parathyroid hormone (Iannotti et al. 1990; Horwitz et al. 1996). The use of rottlerin, however, demonstrated a complete inhibitory effect on $\left[\mathrm{Ca}^{2+}\right]_{\mathrm{i}}$ rise, thus indicating that PKC is involved in the store-independent direct activation of calcium channels. Potential channel targets of PKC activation may include TRPV1 as recent reports have shown that the phosphorylation of TRPV1 requires PKC, protein kinase A and protein phosphatase 2B in embryonic kidney cell line (van Rossum and Patterson 2009).

Previous work has shown an upregulation of TRPV4 (Ali et al. 2008), TRPV1 and TRPV6 (personal observation; data not shown) in human C-20/A4 chondrocytes in response to hypotonicity, further supporting a key role for TRPV channels in chondrocytic mechanotransduction. Therefore to investigate the role of TRPV channels in REV5901-mediated $\left[\mathrm{Ca}^{2+}\right]_{\mathrm{i}}$ rise, chondrocytes were incubated with $10 \mu \mathrm{mol} / \mathrm{l}$ ruthenium red prior to REV5901 loading. Ruthenium red induced an I.F. of $0.46 \pm 0.07$, indicating that TRPV family is involved in transport of $\left[\mathrm{Ca}^{2+}\right]_{\mathrm{i}}$ from extracellular space. It is important to note that our work was partially limited by the non-specific inhibitory effects of ruthenium red on all members of TRPV channels as well as others including NCX as described by others (Gunthorpe et al. 2002).

Similarly to TRPV channels, a role for SACC in mechanotransduction in response to hypotonicity has been previously identified (Kerrigan and Hall 2008) and thus the sensitivity of REV5901-induced $\left[\mathrm{Ca}^{2+}\right]_{\mathrm{i}}$ rise to $\mathrm{Gd}^{3+}$ inhibi- 


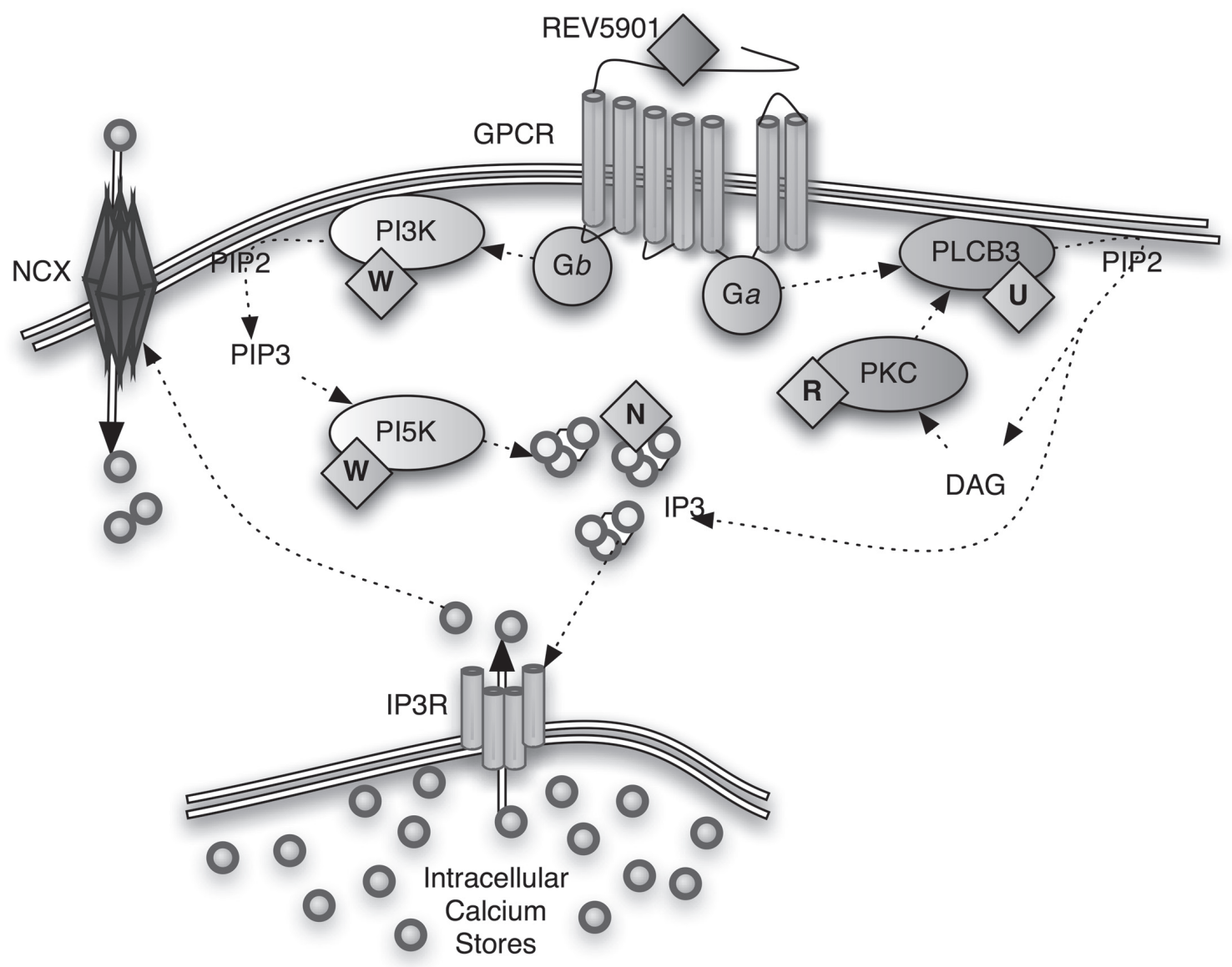

Figure 4. Representative diagram of currently known intracellular calcium signalling pathways. REV5901 has been shown to be an antagonist to cysteinyl-leukotriene receptor, a member of G-protein coupled receptors (GPCR) superfamily. Two potential pathways of action for $\mathrm{G}$-proteins $(\mathrm{G} a$ and $\mathrm{G} b)$ on $\left[\mathrm{Ca}^{2+}\right]_{\mathrm{i}}$ were proposed and investigated; the phospholipase $\mathrm{C}$, beta 3 (denoted PLCB3) and 1-phosphatidylinositol-4-phosphate 5-kinase (PI5K) pathways. We have confirmed that PLCB3 pathway is not involved in REV5901mediated calcium rise as inhibition of PI5K using Wortmannin (W) did not inhibit the calcium rise. Conversely, the use of U73122 $(\mathrm{U})$, rottlerin $(\mathrm{R})$ or neomycin $(\mathrm{N})$, or the inhibition of sodium calcium exchanger (NCX) negatively influenced the maximum change in $\left[\mathrm{Ca}^{2+}\right]_{\mathrm{i}}$ recorded, suggesting that $\left[\mathrm{Ca}^{2+}\right]_{\mathrm{i}}$ manipulating properties of REV5901 acted via the PLCB3 pathway. $\left[\mathrm{Ca}^{2+}\right]_{\mathrm{i}}$, intracellular calcium; IP 3 , inositol triphosphate; PIP3, phosphatidylinositol (3,4,5)-trisphosphate; PIP2, phosphatidylinositol 4,5-bisphosphate; PI3K, phosphoinositide 3-kinase; PKC, protein kinase C; DAG, diacylglycerol; $\mathrm{IP}_{3} \mathrm{R}$, inositol triphosphate receptor.

tion (I.F. $=0.33 \pm 0.04)$ was confirmed here. Finally, the use of sodium-free BPS induced an I.F. of $0.84 \pm 0.09$, whereas upon the removal of extracellular calcium using $2 \mathrm{mmol} / \mathrm{l}$ EGTA, an I.F. of $0.27 \pm 0.08$ was observed, thus indicating a role for NCX in not only mediating calcium influx from extracellular space, but also in stimulating calcium release from intracellular stores. This supports previous observations in rat osteoblasts where a decrease in ATP-dependent $\mathrm{Ca}^{2+}$ release from intracellular store was observed upon the inhibition of NCX using antisense oligonucleotides (Jung et al. 2007).

An unidentified channel has been shown to mediate $\mathrm{Gd}^{3+}$-insensitive rise in $\left[\mathrm{Ca}^{2+}\right]_{\mathrm{i}}$ in freshly isolated bovine articular chondrocyte (Kerrigan and Hall 2008) and this work suggests NCX as a potential candidate whereby sen- sitivity to extracellular sodium was evident. Future research includes investigating the role of individual calcium channels using more selective inhibitors including KB-R7943 mesylate and 6-iodonordihydrocapsaicin, inhibitors of reverse-mode NCX and TRPV1, respectively. Previous work in freshly isolated bovine articular chondrocytes and the chondrocytic human cell line C-20/A4 using thapsigargin, an IP3-independent intracellular calcium releaser, has provided support for store-independent transmembrane influx of $\mathrm{Ca}^{2+}$ ions (Sanchez and Wilkins 2004; Ali et al. 2008). Therefore, the role of PLC $\beta 3 / \mathrm{PKC}$ pathway on membrane calcium channels, whether directly or indirectly via IP3, may be investigated using xestospongin $\mathrm{C}$, an antagonist of IP3 receptor. 


\section{Conclusion}

In conclusion, this is the first report of REV5901-induced rise in $\left[\mathrm{Ca}^{2+}\right]_{\mathrm{i}}$ in freshly isolated bovine articular chondrocytes with a role for PLC 33 -PKC pathway and the NCX (Figure 4). These data have revealed a mechanism via $\left[\mathrm{Ca}^{2+}\right]_{\mathrm{i}}$ by which REV5901 may possibly mediate RVD inhibition and chondro-protective mechanisms.

Acknowledgements. The authors would like to thank Professor Simon Jarvis at the University of Greenwich, and Professor Tajalli Keshavarz at the University of Westminster for their support. We would like to thank Ms Linda Badra-Naber for the moral and financial support of this work. Additionally we would like to acknowledge the Physiological Society for funding Dr. Ala Qusous to present part of this work at the Physiology 2010 Meeting in Manchester, UK. This work was completed at the University of Westminster and the authors would like to thank for its academic and financial support.

\section{References}

Ali N., Qusous A., Getting S. J., Kerrigan M. J. P. (2008): The effect of prolonged hypotonicity on chondrocyte volume regulation and intracellular calcium signalling. Proc British Pharmacological Society 4ed (University of Brighton) 092P

Becker D., Blase C., Bereiter-Hahn J., Jendrach M. (2005): TRPV4 exhibits a functinal role in cell-volume regulation. J. Cell Sci. 118, 2435-2440 http://dx.doi.org/10.1242/jcs.02372

Bush P. G., Hall A. C. (2001): Regulatory volume decrease (RVD) by isolated and in situ bovine articular chondrocytes. J. Cell Physiol. 187, 304-314 http://dx.doi.org/10.1002/jcp.1077

Dascalu A., Korenstein R., Oron Y., Nevo Z. (1996): A hyperosmotic stimulus regulates intracellular $\mathrm{pH}$, calcium, and S-100 protein levels in avian chondrocytes. Biochem. Biophys. Res. Commun. 227, 368-373 http://dx.doi.org/10.1006/bbrc.1996.1514

Davies S. P., Reddy H., Caivano M., Cohen P. (2000): Specificity and mechanism of action of some commonly used protein kinase inhibitors. Biochem. J. 351, 95-105 http://dx.doi.org/10.1042/0264-6021:3510095

Gabellini N. (2004): Transcriptional regulation by cAMP and $\mathrm{Ca} 2+$ links the $\mathrm{Na}+/ \mathrm{Ca} 2+$ exchanger 3 to memory and sensory pathways. Mol. Neurobiol. 30, 91-116 http://dx.doi.org/10.1385/MN:30:1:091

Gandhi C.S., Loots E., Isacoff E. Y. (2000): Reconstructing voltage sensor-pore interaction from a fluorescence scan of a voltagegated K+ channel. Neuron 27, 585-595 http://dx.doi.org/10.1016/S0896-6273(00)00068-4

Gschwendt M., Muller H. J., Kielbassa K., Zang R., Kittstein W., Rincke G., Marks F. (1994): Rottlerin, a novel protein kinase inhibitor. Biochem. Biophys. Res. Commun. 199, 93-98 http://dx.doi.org/10.1006/bbrc.1994.1199
Gunthorpe M. J., Benham C. D., Randall A., Davis J. B. (2002): The diversity in the vanilloid (TRPV) receptor family of ion channels. Trends Pharmacol. Sci. 23, 183-191 http://dx.doi.org/10.1016/S0165-6147(02)01999-5

Hall A. C., Horwitz E. R., Wilkins R. J. (1996): The cellular physiology of articular cartilage. Exp. Physiol. 81, 535-545

Hopewell B., Urban J. P. (2003): Adaptation of articular chondrocytes to changes in osmolality. Biorheology 40, 73-77

Horwitz E. R., Higgins T. M., Harvey B. J. (1996): Histamine-induced cytosolic calcium increase in porcine articular chondrocytes. Biochim. Biophys. Acta 1313, 95-100 http://dx.doi.org/10.1016/0167-4889(96)00057-2

Hou C., Kirchner T., Singer M., Matheis M., Argentieri D., Cavender D. (2004): In vivo activity of a phospholipase C inhibitor, 1-(6-((17beta-3-methoxyestra-1,3,5(10)-trien-17yl)amino)hexyl)-1H-pyrrole -2,5-dione (U73122), in acute and chronic inflammatory reactions. J. Pharmacol. Exp. Ther. 309, 697-704 http://dx.doi.org/10.1124/jpet.103.060574

Iannotti J. P., Brighton C. T., Iannotti V., Ohishi T. (1990): Mechanism of action of parathyroid hormone-induced proteoglycan synthesis in the growth plate chondrocyte. J. Orthop. Res. 8, 136-145 http://dx.doi.org/10.1002/jor.1100080118

James D. J., Salaun C., Brandie F. M., Connell J. M., Chamberlain L. H. (2004): Neomycin prevents the wortmannin inhibition of insulin-stimulated Glut4 translocation and glucose transport in 3T3-L1 adipocytes. J. Biol. Chem. 279, 20567-20570 http://dx.doi.org/10.1074/jbc.C400096200

Jung S. Y., Park Y. J., Park Y. J., Cha S. H., Lee M. Z., Suh C. K. (2007): $\mathrm{Na}+-\mathrm{Ca} 2+$ exchanger modulates $\mathrm{Ca} 2+$ content in intracellular $\mathrm{Ca} 2+$ stores in rat osteoblasts. Exp. Mol. Med. 39, 458-468

Kerrigan M. J., Hall A. C. (2005): Stimulation of regulatory volume decrease (RVD) by isolated bovine articular chondrocytes following F-actin disruption using latrunculin B. Biorheology 42, 283-293

Kerrigan M. J., Hall A. C. (2008): Control of chondrocyte regulatory volume decrease (RVD) by [Ca2+]i and cell shape. Osteoarthritis Cartilage 16, 312-322 http://dx.doi.org/10.1016/j.joca.2007.07.006

Kerrigan M. J., Hook C. S., Qusous A., Hall A. C. (2006): Regulatory volume increase (RVI) by in situ and isolated bovine articular chondrocytes. J. Cell Physiol. 209, 481-492 http://dx.doi.org/10.1002/jcp.20758

Liu B., Wu D. (2004): Analysis of G protein-mediated activation of phospholipase C in cultured cells. Methods Mol. Biol. 273, 99-102

Liu C., Hermann T.E. (1978): Characterization of ionomycin as a calcium ionophore. J. Biol. Chem. 253, 5892-5894

Liu Y., Wang Y., Yamakuchi M., Masuda S., Tokioka T., Yamaoka S., Maruyama I., Kitajima I. (2001): Phosphoinositide-3 kinase$\mathrm{PKB} /$ Akt pathway activation is involved in fibroblast Rat-1 transformation by human T-cell leukemia virus type I tax. Oncogene 20, 2514-2526 http://dx.doi.org/10.1038/sj.onc. 1204364

Muallem S., Wilkie T. M. (1999): G protein-dependent Ca2+ signaling complexes in polarized cells. Cell Calcium 26, 173-180 http://dx.doi.org/10.1054/ceca.1999.0077 
Musser J. H., Chakraborty U. R., Sciortino S., Gordon R. J., Khandwala A., Neiss E. S., Pruss T. P., Van Inwegen R., Weinryb I., Coutts S. M. (1987): Substituted arylmethyl phenyl ethers. 1. A novel series of 5-lipoxygenase inhibitors and leukotriene antagonists. J. Med. Chem. 30, 96-104 http://dx.doi.org/10.1021/jm00384a017

Nair R., Raina S., Keshavarz T., Kerrigan M. J. P. (2011): Application of fluorescent indicators to analyse intracellular calcium and morphology in filamentous fungi. Fungal Biology 115, 326-334 http://dx.doi.org/10.1016/j.funbio.2010.12.012

Nedelcheva Y., Getting S. J., Kerrigan M. J. P. (2010): REV 5901: the protective effect on bovine articular chondrocytes following single impact trauma. Proc. Physiol. Soc. (University of Manchester) UK., PC49

Pan Z., Yang H., Mergler S., Liu H., Tachado S. D., Zhang F., Kao W. W., Koziel H., Pleyer U., Reinach P. S. (2008): Dependence of regulatory volume decrease on transient receptor potential vanilloid 4 (TRPV4) expression in human corneal epithelial cells. Cell Calcium 44, 374-385 http://dx.doi.org/10.1016/j.ceca.2008.01.008

Parker E., Noureen S., Getting S. J., Vleck V. E., Hucklebridge F., Kerrigan M. J. P. (2010): REV5901: Chondro-protective Effects Post Mechanical Trauma. Proc. Physiol. Soc. (University of Manchester, UK), PC156

Parker E. L., Qusous A., Getting S. J., Hucklebridge F., Kerrigan M. J. (2011): REV5901 Induces Calcium Dependant Chondroprotective Effects Post In Vitro Mechanical Loading. Orthopaedic Research Society (ORS) Transactions (Long Beach, CA, USA) 1938

Sackin H. (1995): Stretch-activated ion channels. Kidney Int. 48, $1134-1147$ http://dx.doi.org/10.1038/ki.1995.397

Sanchez J. C., Danks T. A., Wilkins R. J. (2003): Mechanisms involved in the increase in intracellular calcium following hypotonic shock in bovine articular chondrocytes. Gen. Physiol. Biophys. 22, 487-500

Sanchez J. C., Wilkins R. J. (2004): Changes in intracellular calcium concentration in response to hypertonicity in bovine articular chondrocytes. Comp. Biochem. Physiol. A Mol. Integr. Physiol. 137, 173-182 http://dx.doi.org/10.1016/j.cbpb.2003.09.025

Urban J. P., Hall A. C., Gehl K. A. (1993): Regulation of matrix synthesis rates by the ionic and osmotic environment of articular chondrocytes. J. Cell Physiol. 154, 262-270 http://dx.doi.org/10.1002/jcp.1041540208

Van Inwegen R. G., Khandwala A., Gordon R., Sonnino P., Coutts S., Jolly S. (1987): REV 5901: an orally effective peptidoleukotriene antagonist, detailed biochemical/pharmacological profile. J. Pharmacol. Exp. Ther. 241, 117-124

van Rossum D. B., Patterson R. L. (2009): PKC and PLA2: probing the complexities of the calcium network. Cell Calcium 45, 535-545 http://dx.doi.org/10.1016/j.ceca.2009.02.008

Verghese M. W., Smith C. D., Snyderman R. (1986): Role of guanine nucleotide regulatory protein in polyphosphoinositide degradation and activation of phagocytic leukocytes by chemoattractants. J. Cell Biochem. 32, 59-69 http://dx.doi.org/10.1002/jcb.240320107

Waymouth C. (1974): "Feeding the baby"-designing the culture milieu to enhance cell stability. J. Natl. Cancer Inst. 53, 1443-1448

Yellowley C. E., Jacobs C. R., Donahue H. J. (1999): Mechanisms contributing to fluid-flow-induced $\mathrm{Ca} 2+$ mobilization in articular chondrocytes. J. Cell Physiol. 180, 402-408 http://dx.doi.org/10.1002/(SICI)1097-4652(199909)180:3<402:: AID-JCP11>3.0.CO;2-4

Yellowley C. E., Jacobs C. R., Li Z., Zhou Z., Donahue H. J. (1997): Effects of fluid flow on intracellular calcium in bovine articular chondrocytes. Am. J. Physiol. 273, C30-36

Zakharov S. I., Morrow J. P., Liu G., Yang L., Marx S. O. (2005): Activation of the BK (SLO1) potassium channel by mallotoxin. J. Biol. Chem. 280, 30882-30887 http://dx.doi.org/10.1074/jbc.M505302200

Received:August 26, 2011

Final version accepted: February 24, 2012 